\title{
Development of "Water" in Chinese Painting of Modern Times and the Contemporary Age
}

\author{
Wang Kuo \\ Art Teaching Research Office, Beijing International Studies University, Beijing, China \\ Email address: \\ weidadewangkuo@163.com, 1391777848@qq.com \\ To cite this article: \\ Wang Kuo. Development of "Water" in Chinese Painting of Modern Times and the Contemporary Age. International Journal of Literature \\ and Arts. Vol. 7, No. 3, 2019, pp. 66-69. doi: 10.11648/j.ijla.20190703.12
}

Received: April 3, 2019; Accepted: July 25, 2019; Published: July 29, 2019

\begin{abstract}
In traditional Chinese painting, "water" is not only the medium for the harmony of brush and ink, but also the object of landscape painting. It is also the best assistant for Chinese painters to create realms with temperament in artistic creation, while "ink painting" of the contemporary age has already broken through the limitations of tradition, and has become a broader cultural concept or even the pronoun of Chinese elements. It incorporates contemporary art in a more conceptual form, and brings the oriental spirit it represents into the art fields of installation art and experimental art. It combines with new materials to make Chinese paintings show infinite new possibilities. In the future artistic creation, "water" will always play an important role. This paper will reinterpret its value in modern and contemporary art from the aspects of material properties and spiritual values of "water".
\end{abstract}

Keywords: Chinese Painting, Ink Painting of the Contemporary Age, Water Painting, Ink Painting, Materials

\section{Introduction}

In Chinese painting art of modern times and the contemporary age, "water" still plays many roles such as materials, media, tools, objects of expression and spiritual symbols, but there is a new development compared with traditional painting in almost every role. At present, as an independent concept, "ink painting" has no longer limited in such narrow painting type as ink painting or Chinese painting, instead it pushes the value of ink painting to a more diversified concept. Although ink painting, as a traditional Chinese art form, has already made many judgments on the value of ink painting, there are countless theories, inscriptions and postscripts and poems, etc. to repeatedly tell the importance of ink painting in Chinese art. However, contemporary ink painting still broke the monopoly of traditional ink painting and won its own place.

\section{Development of "Ink Painting"}

Contemporary ink painting not just blurs the boundary between the type of painting, expanding the media of ink painting, scope of materials and performance of techniques, but also expresses thoughts, emotions, and spiritual world of contemporary people, to make it more adapt to the contemporary aesthetic requirements, and be able to break through the boundaries of nationality and culture, so as to reach the world. [1]

\subsection{The Contemporary Appeal of "Ink Painting's" Spirit}

It is difficult for people in other countries to understand the traditional ink painting of Chinese painting, who may even often misread, that is mainly because every culture has its own independent aesthetic system and the judgment standard. If one party often look at the other parties from the perspective of its culture, it is difficult to enter the artistic vocabulary of each other and truly experience the party's culture. As Mr. Lu Hong said, "the classification of ink painting in art is based on the material premise of the high perfection of media materials, which are the elasticity of the brush, the fine layer of the ink, the fine and seepage properties of the rice paper. It is self-evident that the high degree of ink painting's expressiveness plays a significant role. Therefore, the media materials used in ink painting itself has been deeply embedded in the impression of national culture." [2] This is congenital gene of the Chinese culture that the ink painting possesses, but there should not be a kind of antagonistic attitude between the east and the west, the 
domestic and the international. In fact, the world becomes smaller and smaller with the intervention of advanced media and communication ways, such as the Internet, and the integration of the global economy, and the gap between culture also have further break condition. The appearance of the ink painting in modern times and the contemporary age, is with a way that is easier for both to understand, so as to communicate with people's emotion of this age in different cultural background. Teacher Yi Ying said, "history cannot replace reality. The more delicate a language is, the less expressive it is. Only by reconstructing the language can it regain its vitality. Of course, what we mainly talk about here is the reflection and performance ability of art language on contemporary society and contemporary culture, rather than cultural connotation and aesthetic value of itself. In terms of ink painting, the poorness of the expression is the indifference of reality, and the reconstruction of the language and the creation of meaning means the return of the reality and life. The collision between the traditional and closed language form and the rich and vivid real life will inevitably lead to new forms of expression." [3] The traditional ink painting was conceived and developed under the ancient agricultural civilization and the feudal social system, and it was an art form in line with the cultural and social concepts at that time. However, in today's era, the colorful city life has replaced the monotony and plain country years, and it is unimaginative for the era before with rapid development of information technology and a variety of media. It has been difficult for the traditional ink painting to completely adapt to the aesthetic requirements of contemporary people, and it has become inevitable for the emergence of the updated language of ink painting and the updated forms of ink painting. As a way of culture, ink painting enters into the context of contemporary art, which must be combined with a variety of different art forms, so the artists who were engaged in other type of artists can also be involved in the exploration and practice of ink painting. They are seldom restricted by the value judgments of traditional ink painting, so, they can use the language of ink painting more purely, which has a positive effect for ink painting to boldly explore new form. Various attempts and rich practical results are also beneficial to the formation of a more open and subversive artistic concept of ink painting. [4]

In terms of spiritual appeal, traditional Chinese ink painting pays attention to understand morality through painting and "treat things with clear mind", so as to achieve an understanding of nature or the laws of the universe in the process of painting. However, the ink painting of the modern times and the contemporary age pays more attention to visual experience and expresses the living state of modern people and cognition and feeling of the world, which is critical and experimental, and it is in line with modern people's knowledge system, cognition mode and ideological standpoint. [5] Nevertheless, in terms of the spiritual understanding and artistic expression of "water" in Chinese painting, people still attach great importance to the understanding of the character and connotation of water in traditional Chinese painting, which is still marked with distinct Chinese cultural labels, because such knowledge is endowed by our own cultural attributes and cultural roots, and it is a common understanding of certain important things that Chinese have long been deeply rooted in. Therefore, even in modern and contemporary Chinese painting, the development of water has been greatly expanded, and the corresponding ink technique becoming more and more abundant. However, Chinese artists still believe that water is a symbol of vitality and vigor and still represents many meanings endowed by Chinese culture of Confucianism, Buddhism, Taoism philosophy in the emotional experience and the understanding of the spiritual connotation about water, which always makes it be widely divergent between Chinese and westerners on "water" and the understanding of the performance object. This kind of phenomenon is not only a reflection of our unique national attributes, but also the root for the art of our country to be distinguished from other countries. However, we still need to study water in Chinese paintings at present, and this is the root of the significance of this study. Therefore, water, as a spiritual support and material carrier in Chinese painting, has been inherited and orderly preserved in the blood of Chinese art, and it can always be the source of inspiration and emotional sustenance for our creation. [6]

\subsection{New Development of "Ink Painting" Techniques}

In terms of techniques, the use of water for modern ink painting is more freedom, such as collage, rubbings, water damage, pour the ink, foil and so on. After break through some ink programs of traditional ink painting, there is less restriction on the use of water, so there can be boldly attempt on the some original ways of water use that do not conform to the requirements of ink painting of the traditional ink painting. There are many ways to use water to make texture effect in modern ink works. For example, a spray can be used to form a uniform punctate texture, which can also be used with salt or detergent on the wet ink to form a special texture effect of water texture. You can also drop color or ink into the water and make it flow naturally in the water, and then put the rice paper on the water to get the natural shape of color and ink flow, so as to use it as a certain texture effect on the picture. Or, use water as a medium to mediate some new materials of modern painting and new media to add layers and richness of painting; even part of the combination of prints or photography to help complete the picture. There are many ways to deal with the picture effect in modern ink painting, and every individual has his own tricks. The development of materials also provides a material basis for water to have a greater play in the creation of modern Chinese painting. Various kinds of paper have emerged, with different textures and different water intake effects which led artists to use water in different ways. In addition, due to the improvement of technological level, many new pigments, new media and new materials keep emerging. Therefore, painters have to make more choices while getting the convenience and new effects brought for them, so as not to 
be kidnapped by the completeness of materials, to let the materials overpower people's thinking. Take a specific example, there are six or seven kinds of gelatin solution that has long been used in the traditional Chinese painting, which can be commonly seen in today's market, and different manufacturers and different brands of products are not included. Gelatin solutions of QIDASEN's art brand are special glue for painting (applicable to reconcile the picture paints and with property of durability), gum Arabic (have strong diffusion and solubility than peach gum), super peach gum solution (can be used in watercolor, gouache or for special effects processing), super gelatin solution (applicable to the ink painting, gouache, traditional Chinese realistic painting), super glue water alum and super sticky glue, etc. Many mediate media of ink painting and catalysts that haven't been heard by predecessors have appeared, such as separation flow agent, black catalyst, coffee run-ink agent, special water for development and catalytic, special water for separation and flow and so on. These materials undoubtedly provide convenience for modern painters to seek special effects of ink painting, but for many works of ink painting in the contemporary age, ink painting has become a symbol or cultural spirit, and they only keep a comparatively broad vision or cultural relation with the traditional ink painting. Sometimes, water and ink has become a kind of indicative existence without actually appearing in the works, while especially the focus for some equipment of ink painting, image of ink painting and performance art of the contemporary age is the contemporaneity instead of the ink painting itself.

The artist Zhang Yu once said in Zhang Yu's Talk on Experimental Ink Painting that many painters of ink painting would customize special paper to meet their own requirements according to the special needs of their paintings. The rice paper he used on the finished work of "Finger Print" is very special, because the rice paper can produce some slight concave and convex changes after it comes into contact with water. And the rice paper can produce concave and convex layers in space due to his different movements, dynamics and moisture when he repeats to paint the ink, so that the works can be performed from the two-dimensional space changes into the three-dimensional space. For people watching works, this change will also enrich the visual experience of people. The innovation of materials here plays a significant role in creating new artistic effects and visual experience, and the use of water also goes beyond the previously limited scope of changes in the two-dimensional plan, so as to become a tool to shape three-dimensional space. [7]

The works of artist Liang Quan are mostly abstract ink painting, and his use of water is different from that of traditional ink works. In his works such as "Cold Spring" series, "Tea and A Little of Coffee" series, "The Diary of My Tea" series, "Point", "Trace" and so on, all took the tea, ink, color and paper collage as main creation materials. First is to use different liquid to form water stain or tea stain that is similar to circle shape with different size, color and posture, and then collage the water stain with the paper to form a orderly sequence or sequence of expressing special meanings, so as to complete the creation of a piece of work. For another example, his works such as "Iron Casting After Rain" series, "Untitled" series, "Eight Scenes of Xiaoxiang" series, "Water is Flowing" series and "Hidden Map of Qingxi Fish", put a lot of thinking on each piece of rice paper used for collage, and the size, length and ink color of each piece of rice paper all had subtle changes. And then, reasonably organized and integrated to form a picture through the analysis of the painter's aesthetic and visual experience, because different combinations naturally reflected different themes and different moods that the painter wanted to express. Liang Quan's works make people feel peaceful, and the exquisite arrangement on the subtle place can be found after careful reviewing, which are the works of ink painting that are worth appreciating. The ancients rarely painted water stains into the painting, and they also not used it as the main means of creation or even the only means. However, Liang Quan created a series of abstract ink works by means of water, ink and tea stains, which was the originality of him, and that is also the reason why it was so different from the traditional Chinese painting on the understanding and use of water stains. There are some new breakthroughs differed from the tradition from techniques to the understanding of water as a medium. [8]

Except the artists like Zhang $\mathrm{Yu}$ and Liang Quan who made breakthroughs in tools and techniques, there are artists like Wang Tiande who gave up water to express the meaning of ink painting. In series of Digital, he tried to use ink, flame, vellum and rice paper as materials to create works, which expressed the forms of Chinese ink landscape and calligraphy, through the way of burning. Water and fire, the two completely different media, has produced such a harmonious symbiosis in his hands. In addition, he also tried to burn the copybooks published by Xiling Publishing House into ashes, and then used the ashes to pile up various "solitary mountains". If water represents life in traditional Chinese culture, then fire represents devastation and destruction, but after all is lost, fire also symbolizes rebirth. The fire of destruction and rebirth burned on rice paper printed with traditional ink and calligraphy, which may be the reason why the painter rebelled against and remold the concept of traditional ink and made full use of the cultural symbolism of ink to actively make their own artistic experiments. It breaks down the boundary of ink painting and tries to explain that the style of ink painting is not important, but what important is the cultural origin we want to preserve or our "oriental spirit". [9]

\section{Conclusion}

Taking ink painting as the main media, emphasize concepts of the ink painting installation and performance art, which have probably already gone beyond the traditional category of ink painting, but instead it becomes an installation art or other visual art form that regards ink 
painting as the way for expressing specific concepts. From the experiments of these artists, we can see that they are actively introducing ink painting as a symbol or concept into the creation of contemporary art, trying to participate in the construction of contemporary art system with their unique national identity. "The concept of contemporary not refers to all works exist at the moment, but refers to a kind of art with special intention and the construction of theory. The intent refers to declare the unique historic property of work itself through the this construction, therefore, artists and theorists will think consciously the situation and limitations of 'modern and contemporary', with personalized reference, language and ideas to make the conventional concepts of time and place of 'modern and contemporary' essential." [10] As a result, the water, as part of the ink painting ontology, in the contemporary context, has become a concept or symbol of something in a lot of works that emphasize on the concept, but this kind of concept can not be separated from the expression that Chinese traditional culture make on them. In terms of techniques, the tools and materials people choose are all under the control of ideas or intentions, because material is probably the least important factor for contemporary art.

Of course, many contemporary painters have contributed to the exploration of techniques, but I won't list them here because they are not the core of this thesis. With the continuous development of process and technology, numerous new tools, new materials and new concepts will be gradually integrated into the creation of contemporary Chinese art, which not only injects vitality and development potential into Chinese painting, but also puts forward some challenges to our creation. How can we make the art of our country go deeper into life in line with the requirements of the ear without losing our national identity and excellent traditions? This is probably a question worth all of our painters to ponder.

\section{References}

[1] Lu Hong, History of Chinese Contemporary Art from 1978 to 2008, Hebei Fine Arts Publishing House, 2014.

[2] Lu Hong, Twenty Years of Modern Ink Painting, Changsha: Hunan Fine Arts Publishing House, 2002.

[3] Yi Ying, The Meaning of Creation. Jiangsu Pictorial Magazine:1st issue of 1994: 13.

[4] Chen Chuanxi, The History of Chinese Painting Aesthetics, People's Fine Arts Publishing House, 2012.

[5] Liu Ming, the spirit of modern ink and wash, beauty and the times, 2015-08.

[6] Xu Fuguan, Chinese Art Spirit, Guangxi Normal University Press, 2012.

[7] Zhang Yu, Ink Language Approach to Contemporary Art, Oriental Art, 2015-05.

[8] Zhu Liangzhi, The 15th Lecture on Chinese Aesthetics, Peking University Press, 2013.

[9] Pi Daojian, Evaluation Standard for Contemporary Ink and Wash, World of Public Relations, 2016, Issue 20.

[10] Wu Hong, Works and Exhibition Field -- The Discussion about Contemporary Chinese Art of Hong Wu, Guangzhou: Lingnan Art Publishing House, 2005. 